\title{
Para além do unidimensional: Marcuse e a educação estética
}

\author{
Vivian Baroni \\ Universidade de Passo Fundo
}

\section{Resumo}

0 presente artigo visa abordar o conceito de educação estética subjacente à obra de Herbert Marcuse. Procuramos demonstrar como a valorização da dimensão artística aliada à educação tornaria possível repensar o conceito instrumental de razão, fornecendo ainda subsídios para a elaboração de um conceito qualitativo de desenvolvimento baseado na redefinição da cultura. Trabalhamos com a hipótese de que, em virtude das qualidades críticas e transformadoras da arte, a educação estética fomenta um conceito crítico de razão, capaz de conduzir uma apreensão da realidade que ultrapassa a mera adaptação para se posicionar na resistência e na promoção de novas formas de existência.

Palavras-chave: Marcuse. Educação estética. Razão crítica. 


\section{In addition to the one-dimensional: Marcuse and the aesthetic education}

This article aims to address the underlying concept of aesthetic education to the work of Herbert Marcuse. To demonstrate how the valuation of the artistic dimension along with education makes it possible to rethink the concept of instrumental reason, even providing subsidies for the development of a qualitative concept of development based on the redefinition of culture. We hypothesized that, given the critical and transformative qualities of art, the aesthetic education fosters a critical concept of reason, able to conduct a grasp of reality that goes beyond mere adaptation to position the resistance and the promotion of new forms of existence.

Keywords: Marcuse. Aesthetic education. Critical reason.

\section{Hacia el más allá de lo unidimensional: Marcuse y la educación estética}

Este artículo tiene como objetivo abordar el concepto subyacente de la educación estética de la obra de Herbert Marcuse. Pretendemos demostrar cómo la apreciación de la dimensión artística junto con la educación permiten repensar el concepto de la razón instrumental, incluso dando subsidios para la elaboración de un concepto cualitativo de desarrollo basado en la redefinición de la cultura. Trabajamos con la hipótesis de que, dadas las cualidades críticas y transformadoras del arte, la educación estética fomenta un concepto crítico de la razón, capaz de llevar a cabo una comprensión de la realidad que va más allá de la mera adaptación a la posición de la resistencia y la promoción de nuevas formas de la existencia.

Palabras-clave: Marcuse. Educación estética. La razón crítica. 


\section{Introdução'}

A deturpação do conceito emancipatório de razão, contido no projeto Iluminista e seu direcionamento para o sistema capitalista de acumulação, fez com que a racionalidade se tornasse não só um instrumento de dominação da natureza, mas também um meio de regulação social em que a própria ação do homem tornase objeto de controle. Esse novo paradigma racional reflete-se diretamente nos processos formativos, que, regulados pela noção de superficialidade da emancipação intelectual, dirigem as esferas formativas para a função prioritária de adaptar os indivíduos à sociedade e ao processo de trabalho, deixando em segundo plano a formação de resistência ao sistema econômico e o fomento de condições que possibilitam a superação do status quo.

Para Marcuse, a emancipação funda-se essencialmente no conceito de razão crítica: no esforço da crítica em ultrapassar o dado imediato e transcender o raciocínio condicionado ocorre o processo de formação como emancipação. A racionalidade bidimensional, caracterizada pelo pensamento negativo, não se esgota na crítica da realidade, mas propicia uma mediação com o real capaz de ultrapassar a esfera da adaptação para ancorar o pensamento em elementos novos que podem conduzir para a transformação da realidade. Ou seja, a razão crítica compele também a uma práxis política que busca a superação da realidade.

Em um momento histórico marcado pelo apelo ao pragmático, a redução da formação à transmissão de conhecimentos técnicos voltados para a habilitação dos estudantes para o mercado de trabalho favorece o surgimento de uma consciência reificada e de uma relação consumista com as produções culturais, contribuindo para o atrelamento da educação às exigências heterônomas. Nesse sentido, a ênfase de Marcuse na dimensão estética aponta diretamente para a necessidade do resgate de uma racionalidade guiada pelo pensamento negativo, que no sentido hegeliano contempla não somente a crítica do estado de coisas, mas também a potencialidade dialética do vir a ser. 0 contato com os clássicos e com as produções artísticas representativas dos âmbitos mais altos de refinamento intelectual propiciam a mediação com o real em uma análise que não se esgota na adaptação a ela, mas coloca em evidência outros elementos, desconhecidos até então, que podem conduzir para além da existência dada, mostrando relações e possiblidades de sua superação.

Tendo por base a análise da obra tardia de Marcuse, o presente artigo visa investigar o conceito de educação estética, subjacente aos escritos marcuseanos,

1. Uma versão preliminar do presente ensaio foi apresentada no V Seminário Internacional sobre Filosofia e Educação, ocorrido no período de 10 a 12 de setembro de 2014, na Universidade de Passo Fundo (UPF/RS). 
procurando demonstrar como a educação estética torna possível repensar o conceito repressivo de razão instrumental, e um possível paradigma de desenvolvimento qualitativo baseado na redefinição da cultura. Trabalhamos com a hipótese de que, em virtude da negatividade dialética presente na arte autêntica, a formação cultural fomenta o desenvolvimento do pensamento crítico, que, no esforço em ultrapassar o dado imediato, resulta em uma formação que gera inquietação e anseios de mudança.

\section{A redefinição da cultura e a transformação da racionalidade}

Marcuse procurou concentrar as possibilidades emancipatórias em torno do que chamou "redefinição da cultura". Para Marcuse (1998), a cultura deveria ser entendida como o complexo de objetivos morais, intelectuais e estéticos considerados por uma sociedade, como meta a ser alcançada mediante o modo de vida por ela adotado. Ou seja, somente podemos nos referir à cultura, passada ou presente, quando seus valores e objetivos representativos são reconhecidamente traduzidos na realidade social. Nesse caso, a sociedade é responsável por fornecer uma base para a realização possível desses valores, o que demonstra uma noção de cultura que não se restringe à esfera ideal, mas que faz parte da objetividade do mundo material.

Segundo Marcuse (1978), a maneira pela qual a vida dos indivíduos é definida pela sociedade compreende fundamentalmente uma determinada escolha inicial entre alternativas históricas que são determinadas pelo nível de cultura material e intelectual herdado. No entanto, a escolha é resultado do jogo de interesses dominantes que antevê maneiras específicas de utilizar o homem e a natureza e rejeita outras. Assim, pode-se compreender como o paradigma racionalista de emancipação, ao ser direcionado para a dominação dos homens e das coisas e aliar-se ao sistema capitalista de acumulação, transforma-se em um meio de regulação social, em que a própria ação humana torna-se objeto de controle. Consequentemente, a revisão de uma cultura deverá prever a questão da relação dos valores com os fatos como um problema da própria estrutura social, não devendo circunscrever-se à esfera ideal, mas ser incluído como uma questão essencial a ser resolvida pela e na práxis política.

Na medida em que o sistema econômico necessita da utilização da cultura como um instrumento ideológico de constituição de uma subjetividade passiva, o emprego dos conceitos básicos da antiga cultura afirmativa burguesa se mostra profícuo, ajudando a compor um programa de "educação cultural”. Essa educação visa à eliminação da negatividade dialética da cultura mediante a sua massificação 
e o rechaço aos âmbitos transcendentes e teóricos da tradição intelectual, que são capazes de fazer frente à sociedade estabelecida. A contribuição de Marcuse com a análise da cultura afirmativa evidencia os alicerces ainda ocultos da manipulação da massa, tanto em termos culturais, quanto nos termos da sociedade de consumo: "As bases no plano material-sensível em que se sustentam, enquanto satisfação aparente e transitória, os mecanismos de obstrução dos potenciais emancipatórios" (Maar, 1998, p.64). Logo, para ser afirmativa, a cultura em seu viés ideológico precisa operar no âmbito da referência material-sensível, mas, ao mesmo tempo, tem que evitar nesse nível a potencialização cultural-formativa de demandas materiais-sensíveis cerceadas na prática produtiva real.

A formação cultural do sujeito inserido no panorama da sociedade unidimensional “se articula à cultura objetiva nos parâmetros da relação entre uma semiformação como travamento da experiência emancipadora e uma semicultura, unicamente afirmativa e sem potencial crítico" (Maar, 2003, p.67). Nesse contexto de "deseducação cultural", uma das principais formas de se construir uma subjetividade passiva, tanto no nível da formação institucional quanto informal, se dá por meio da eliminação da dimensão de negação da cultura. A contradição latente entre a dimensão autônoma da cultura e as condições heterônomas da realidade que a negam exige a supressão dos elementos que mostram a realidade como contraditória. Esse processo se dá por meio da incorporação sistemática da cultura na civilização, reprimindo a tensão entre as duas esferas constituidoras da realidade. (Marcuse, 1998)

A aceleração das mudanças tecnológicas e a articulação do desenvolvimento técnico-científico com o capital global aumentaram assustadoramente o poder da racionalidade unidimensional no interior dos processos formativos. A rapidez com a qual o conhecimento perde validade no âmbito da informática e o aumento crescente da participação de uma cultura afirmativa e massificada no processo de formação apresentam um panorama desafiante para se refletir a ação educativa hoje. No entanto, segundo esse panorama, podemos pensar que, se a cultura repressiva da sociedade trabalha para mistificar as relações humanas e aniquilar a subjetividade crítica, cabe à educação inverter essa fórmula. Ou seja, acionar processos formativos que revertam a aculturação com finalidades servis e mantenedoras do estado de sujeição do homem ao aparato técnico.

Neste sentido, o projeto marcuseano de redefinição da cultura e a sua ênfase na educação estética apontam para um projeto formativo que resulta em uma práxis política: formação como educação dos sentidos para a interação crítica e transformadora com a realidade social. No aprimoramento da percepção estética surge uma nova sensibilidade que possibilita aos sujeitos transcenderem a mera razão instrumental com que atuam na transformação da natureza. Para 
Marcuse, é por meio da arte que o homem se educa e reeduca constantemente a sua condição de superioridade em relação à instrumentalização da natureza, para então humanizar-se: libertar-se da reificação e conduzir, mediante a razão crítica, um projeto emancipatório. Se a cultura hegemônica limita e determina a experiência nos âmbitos mais avançados da civilização, o faz somente porque necessita ocultar as alternativas reais de transformação da realidade.

Para Marcuse (1998), a relação entre cultura e civilização havia se alterado em virtude da sociedade tecnológica e da racionalidade instrumental que a gere. Logo, para que o projeto formativo de emancipação seja efetivado, é necessária uma redefinição radical da cultura estabelecida, que impede a tomada de consciência dos indivíduos e barra o surgimento das necessidades de libertação. Orientando-se para o estabelecimento de uma cultura que possa guiar as metas morais, intelectuais e estéticas na direção da emancipação subjetiva e material está um conceito de razão crítica que é ancorado nas dimensões qualitativas do conhecimento: a arte, a filosofia, a ciência teórica, etc. Conforme Marcuse, é em torno dos conceitos da razão crítica, que são ao mesmo tempo filosóficos, sociológicos e históricos, que se encontram os catalizadores espirituais dessa nova cultura: "Eles abrem uma oportunidade intelectual que talvez conduza ao nascer de novos projetos sociais, a novas possibilidades de existência" (Marcuse, 1998, p.167). A importância do restabelecimento de uma razão crítica fundamentada nos âmbitos teóricos do pensamento mostra-se quando lembramos que a cultura tanto espiritual quanto material, mesmo em seus projetos práticos, foi projetada pela ciência, literatura e filosofia antes de se tornar uma realidade. Ou seja, a redefinição da cultura deve iniciar sobretudo na transformação de seus pressupostos teóricos.

Esse fato implica a necessidade de transformação do paradigma instrumentalista de razão sob o qual se funda a ciência moderna, recuperando as antigas metas de fundação da civilização como meio de pacificação da luta pela existência. Para tanto, Marcuse define a revalorização da cultura não científica como um fator importante da transformação da ciência. 0 isolamento da realidade e a ênfase na interioridade proporcionada pela cultura burguesa permitiram à arte estabelecer um refúgio no qual puderam sobreviver as imagens esquecidas ou reprimidas pela sociedade, constituindo o contraponto teórico da racionalidade instrumental: "Se a sociedade (com os meios científicos) contribui para a coordenação e a administração total, então a alienação da cultura não-científica converte-se na precondição da oposição e da recusa". (Marcuse, 1998, p.171)

É preciso considerar que a cultura cientifica não é a única responsável pelo desenvolvimento e pelo progresso, pois os âmbitos da pesquisa não científica agrupados em torno dos modos de pensar não conformista e crítico-transcendental são também constitutivos da racionalidade. A ênfase da racionalidade científica na 
valorização das ciências exatas agrava-se quando consideramos essa prerrogativa de validade como uma afirmação de legitimação universal a uma determinada teoria e prática histórica específica da ciência, considerando outros modos de conhecimento como imprecisos ou menos científicos e, consequentemente, menos verdadeiros. Para Marcuse, a redefinição da cultura deverá prever, no âmbito dos processos educativos, a revalorização das disciplinas de caráter essencialmente teórico.

A importância da preservação do universo de pesquisa, que guarda em si a contradição com o existente, mostra-se na necessidade de constituição de uma resistência, por parte do processo formativo, em não permitir em seu interior a inserção do pensamento positivista. Conforme Marcuse (1998, p.166), a educação pautada no positivismo "serve muito frequentemente para cortar a raiz da autodeterminação no espírito do homem - uma autodeterminação que significa hoje (como no passado) a desvinculação crítica do universo da experiência". 0 processo formativo conduzido pelo positivismo, que toma o objeto como uma construção técnica predefinida, reduz as relações mundo-objeto à mera instrumentalidade, fazendo com que a noção de conhecimento que brota daí só possa ser a mera descrição em termos reificados. A partir do momento em que os valores e qualidades humanas, tais como a essência do homem e a liberdade, são submetidos aos modelos de pesquisa mensuráveis, "os antagonismos entre o ser e o dever ser, existência e essência, são literalmente absorvidos, mas em detrimento do dever ser e da essência". (Nicolas, 1971, p.108)

\section{Educação estética e resistência}

Para Marcuse, a resistência que deve ser fomentada pelo processo formativo se resume à construção de uma razão crítica, desenvolvida no contato com os âmbitos do conhecimento em que o pensamento negativo logrou sobreviver: a arte e as ciências humanas e teóricas. Conforme Maar (2003), é no conceito de resistência que reside o espaço para uma dialética da emancipação: a relação com a realidade, apreendida como contradição, ressalta a necessidade de não se limitar à adaptação, mas recorrer à resistência contra a adaptação, no que significa a imposição da realidade como algo meramente exterior, não apreendida numa relação de experiência. Nesses termos, a razão crítica compreende uma relação ambígua com a realidade, enquanto adaptação e enquanto inadequação. Assim, a razão é essencialmente negativa: "Ela se torna o que realmente é pela relação com o que não é” (Maar, 2003, p. 63), e é nesse vai-e-vem dialético que é possível atingir o objetivo de realizar a essência humana. 
É nesta síntese entre o negativo e o positivo, o real e o possível, que a obra de arte se substancia enquanto forma e aparência, o que qualifica a estética como uma categoria do conhecimento. Nisso, a sua práxis política se revela como educação dos sentidos na interação dos sujeitos com a realidade: os sentidos mais atentos e dinamizados pela experiência estética propiciam uma visão diferente da imposta pala sociedade, o que permite enxergar além da aparência. Logo, a educação estética pode reverter o embotamento dos sentidos dirigido pela racionalidade unidimensional mediante uma perspectiva de estetização como experiência formativa. Mais ainda, é na consciência das contradições sociais que a forma estética permite ao indivíduo a possibilidade de uma consciência objetiva, pois a arte não consiste apenas em uma expressão meramente subjetiva, no sentido de traduzir a realidade a uma mera idiossincrasia. Para Marcuse, a projeção na objetividade é um requisito básico de toda obra de arte autêntica: sua ação permite reverter a percepção objetificada com que o sujeito é levado a introjetar o mundo.

Assim, o processo formativo conduzido pelo viés da contradição possibilita a gestão de metas e estratégias que visam à transformação revolucionária da sociedade. No entanto, as modificações constantes na estrutura do capitalismo alteram as bases para o desenvolvimento e a organização das forças potencialmente revolucionárias. Para Marcuse (1969), as metas e as ocasiões imediatas da ação são determinadas mais pelas situações cambiantes da estrutura capitalista do que por uma estratégia bem fundada e elaborada. Esse fato implica a importância da valorização dos fatores subjetivos: o desenvolvimento da consciência e das necessidades libertárias. Se sob a administração capitalista a formação é dirigida para a determinação social da consciência, a necessidade primária é a mudança radical da consciência como primeiro passo para a transformação social da existência.

Aqui se destaca a importância dada por Marcuse à educação para esse processo: “Historicamente, é outra vez o período da ilustração que precede a mudança material - um período de educação, porém, educação que se converte em práxis: demonstração, confrontação, rebelião" (Marcuse, 1969, p.58, tradução nossa). Ou seja, cabe aqui um conceito de emancipação como formação que habilite, por meio da crítica da experiência, uma compreensão ampla das contradições que moldam a cultura e a sociedade, que se reflete na transformação da própria experiência. A ênfase nos processos subjetivos aponta para a importância da existência de uma educação política em ação que ative a contradição manipulada e reprimida, utilizando-a como um catalizador da mudança. (Marcuse, 1969)

A tarefa básica é a educação, mas educação em um sentido novo, como formação universal das potencialidades do homem: "Hoje, a educação deve compreender o espírito e o corpo, a razão e a imaginação, as necessidades intelectuais e o instinto" 
(Marcuse, 1986, p.114, tradução nossa). Não se trata de politizar a educação, pois ela já é política, mas sim iniciar uma contrapolítica, oposta à política estabelecida. Trata-se de estabelecer uma formação para a resistência, fazer frente à sociedade em sua própria base material.

Para Marcuse, a revolução seria baseada na liberação dos sentidos, da percepção. A constituição de uma consciência feliz impede a visão das contradições em uma relação mediada pela racionalidade unidimensional, fazendo com que a percepção seja resultado de uma construção predefinida pela sociedade. No entanto, por meio da arte é possível desconstruir a visão reificada imposta pela cultura estabelecida, pois mediante a transformação do conteúdo pela forma estética é permitido vislumbrar a realidade ora como ela é, ora como deveria ser. A arte tem o poder de fazer nascer uma subjetividade rebelde, na qual a percepção seja livre da influência prejudicial da sociedade.

Tendo em vista essas considerações, nos é possível afirmar que os processos formativos conduzidos pela dimensão estética poderiam ser capazes de libertar a consciência das formas de reificação que a afetam. Em virtude das qualidades da crítica e necessidade de mudança esboçada pela arte, uma educação estética possibilita um conceito político de formação. Seu valor reside na tentativa em reconstruir a noção de cultura enquanto força política. 0 contato com os clássicos e com a ciência teórica abre um horizonte de possibilidades de problematização da realidade que reafirmam a necessidade de transformá-la. A apropriação crítica da realidade resulta, por sua vez, em uma noção de conhecimento que é transcendente não somente em sentido epistemológico, mas, sobretudo, em relação ao posicionamento contrário às forças repressivas da existência, ou seja, essencialmente político (Marcuse, 1969). As demandas resultantes desse processo educativo impulsionam, assim, a um movimento que ultrapassa a esfera formativa institucional da escola e da universidade.

A principal exigência da revolução passa a ser a mudança qualitativa como subsídio principal para fundamentar um outro princípio da realidade ${ }^{2}$. Conforme Stederoth (2003), a transformação qualitativa representa uma revalidação dos valores que surgem como máxima para o conceito estético-crítico de educação marcuseano, na medida em que esse conceito implica duas dimensões essenciais: 1) oferece, por meio da abertura de novas percepções, um olhar crítico e reflexivo sobre o presente sócio-histórico; 2) com essa abertura, descortina um horizonte no qual se tornam visíveis os contornos de uma nova sociedade orientada sob o ideal estético.

2. Aqui, o termo se refere ao conceito freudiano, aquele que designa a repressão pulsional necessária para que haja a civilização. 0 tema é tratado especificamente por Marcuse na obra Eros e civilização (1975). 
Tal qual a arte, a educação também não pode transformar o mundo, a materialidade imediata, mas apenas fazer surgir nos espíritos a necessidade da mudança e as condições ideológicas necessárias para a sua efetivação. De fato, a revolução não é um processo espontâneo, mas sim uma ação humana que depende fundamentalmente da consciência e da subjetividade. A crítica de Marcuse à desvalorização subjetiva encabeçada pela estética marxista demostra a necessidade da valorização política das formas imateriais, pois uma prática política de transformação das condições materiais "sem a crítica permanente da racionalidade, sem o momento de transformação da subjetividade destituída de experiência formativa, não seria emancipatória”. (Maar, 2003, p.80)

Pode-se afirmar que a transformação subjetiva inicia com a problematização consciente e crítica da realidade social, procurando compreendê-la para além das aparências, da imediatidade e dos discursos ideológicos que a moldam, necessitando para isso de um substrato teórico, ou conforme Saviani e Duarte (2012), das abstrações teóricas encontradas na filosofia e na arte autônoma, que possibilitem a transcendência para além do dado imediato. No entanto, pensar a realidade a partir de abstrações e modelos teóricos de pensamento, caracterizados pela dialética e pelo pensamento negativo, é uma capacidade que não se forma espontaneamente nos indivíduos, mas que precisa ser fomentada deliberadamente. Para tanto, é necessário que o processo educativo tenha como uma tarefa básica o desenvolvimento da percepção estética que permita o contato com os clássicos, com as obras de arte, desde o seu início. Ou seja, uma educação estética implantada ainda na infância torna possível a apropriação crítica das obras de arte, que influenciam decisivamente a construção da subjetividade crítica.

Nas palavras de Saviani e Duarte (2012), se a revolução é uma das mais expressivas formas de criatividade humana, resultando na criação de uma nova realidade, então podemos considerar a revolução não como um ato místico ou irracional, mas sim o resultado de um acúmulo social de experiências, ao que Marcuse (1998) acrescenta: o cultivo de capacidades espirituais e de consciência intelectual que não estejam adaptadas às formas de agir e pensar da civilização dominante nos países industriais avançados.

No processo revolucionário ocorre um salto qualitativo na sociedade que transforma fundamentalmente as relações sociais, porém, tal salto só se confirma quando existe o domínio consciente das contradições que formam a realidade. Nesse sentido, a importância dada por Marcuse ao trabalho de tornar a consciência crítica qualifica a constituição da subjetividade como um elemento central do materialismo histórico. 0 processo revolucionário é mais do que um processo de tomada de poder político e econômico, mas envolve, sobretudo, mudanças essenciais nos próprios indivíduos e na sociedade. 
Porém, em uma sociedade que alcançou certo grau de pacificação, pensar na ideia da revolução parece desnecessário, até mesmo loucura. 0 problema consiste em modificar a própria vontade, de modo a evitar que as pessoas continuem desejando o que querem agora. Mas como mostrar a necessidade da revolução em uma sociedade relativamente satisfeita? 0 caminho que sugere Marcuse encontrase subjacente ao conceito de formação kantiano, em que a superação do estado de menoridade implica a decisão de romper com a incapacidade do homem em servir-se de seu próprio entendimento sem a orientação de outro, para alcançar a maioridade - o estado em que não há dependência de autoridade externa nem da superstição incrustado no interior do sujeito. Para Marcuse, a real emancipação deve ser aquela que permita não só ao sujeito a liberdade de ação, mas também uma mais profunda e essencial: a liberdade de consciência.

E se a crítica e o reconhecimento da situação histórica assim como das contradições da realidade podem ser qualificados como a mola propulsora da transformação da realidade, então a educação estética não se refere somente a conteúdos intelectuais que poderiam conformar uma consciência verdadeira, mas sobretudo ao caráter materialista da consciência: como faculdade, aptidão à prática, disposição à experiência autêntica, formativa. Assim, a formação cultural não se refere a uma mera necessidade intelectual, mas uma necessidade propriamente material, porque tem a ver com ideias enquanto diretrizes para a concretização da essência humana. (Maar, 2003)

Os esforços de Marcuse por derivar uma teoria estético-educacional da filosofia, oriunda principalmente da dialética alemã, põem em evidência a necessidade da abordagem dialética da cultura, implicando uma postura tanto de combate contra a "falsa" cultura, como também em favor da cultura que pode guiar a libertação. A formação, que nos últimos tempos vem se reduzindo unicamente à instrução, reflete a crise histórica pela qual passa também a ciência e a sociedade: a transformação da razão em racionalismo. Nesse sentido, a tarefa essencial da teoria crítica deve ser a de analisar a formação social em que se dá esse processo, revelando as raízes desse movimento e descobrindo as condições para interferir em seu rumo. A questão primordial é pensar a formação em seu devir, pois só assim é possível fixar alternativas históricas tendo como base a emancipação.

Para Marcuse, a tarefa fundamental da educação seria a de preparar os indivíduos para uma nova hierarquia de valores e necessidades. Guiados pelo objetivo da humanização e da pacificação, a nova sensibilidade que os compõe torna-se até mesmo uma ameaça para as instituições estabelecidas. Como parte de um processo de contrarrevolução movido pelas instituições conservadoras, a educação absorve parte do processo econômico prevalecente na sociedade, e personificada por meio da chamada educação tradicional trabalha para a 
manutenção da estrutura do poder. A contradição entre a educação atual e a libertadora mostra-se quando constatamos que, ao mesmo tempo que a sociedade estabelecida possui as condições para a implantação de uma educação para uma sociedade melhor, uma educação assim seria uma ameaça tangível para a sociedade estabelecida. (Marcuse, 1986)

Se conforme Kant, o objetivo da educação das crianças não é o de prepará-las para o presente, mas sim para uma condição futura, de acordo com a espécie humana, então esse objetivo implica a subversão da atual condição do homem. E na medida em que agora se dispõe dos recursos técnicos e materiais para o desenvolvimento de uma sociedade livre, a possibilidade de sua realização depende apenas das forças humanas, sociais, que necessitam de uma sociedade assim, não somente objetivamente, mas também subjetivamente. (Marcuse, 1986)

Uma educação segundo essa concepção implicaria a imunização de adultos e crianças contra os meios de comunicação de massa, um acesso total à informação eliminada ou deformada por esses meios, a organização do protesto e da negação efetivas que não acabem no martírio de quem nega e contesta, etc. Essa educação aponta também para uma transmutação de valores centrada na tarefa de desmascarar todo o heroísmo a serviço da inumanidade, o esporte e a diversão a favor da brutalidade e da estupidez, a crença na necessidade da luta pela existência e na necessidade dos negócios. Embora esses fins de uma nova educação apareçam como negativos, é preciso ressaltar que a negação é a obra e o modo de aparição do positivo. Ou seja, é preciso criar um espaço físico e intelectual no qual possam se desenvolver as características de uma existência humanizada, sendo exigida para isso a eliminação do material devastador e sufocante que ocupa esse espaço na atualidade. (Marcuse, 1986)

0 diagnóstico marcuseano da cultura permite visualizá-la como uma construção em que ideologia e poder se mesclam, ora em favor da sociedade repressiva, ora como instrumento de luta política pela sua superação. A apropriação da cultura emancipatória pela práxis educacional permite que a força de sua união volte a definir a política do poder, colocando a centralidade da pedagogia político-cultural como um princípio que define a mudança social (Giroux, 1986). No entanto, para isso é necessário que a educação não seja vista como uma força neutra na sociedade, mas sim marcada essencialmente pela dialética entre interesse social, poder político e econômico de um lado, e conhecimento e prática escolar de outro.

Marcuse marcou seus estudos em diversas direções de pesquisa, como a crítica da racionalidade positivista e a noção de sensibilidade radical, além da psicanalise e da filosofia. No entanto, o que constitui a pedra fundamental de seu pensamento é a noção de repressão enquanto subjacente à racionalidade adotada pela ciência e pela sociedade, além da necessidade do desenvolvimento de uma 
consciência crítica e de uma nova sensibilidade que assumam um discurso de oposição como pré-condição para a emancipação. Para tanto, Marcuse considera que o surgimento de uma nova sensibilidade, resultante do contato com a arte, possibilita a superação do paradigma de desenvolvimento quantitativo por uma perspectiva qualitativa.

\section{Imaginação, sensibilidade e razão: a realidade guiada pela educação estética}

No ensaio A nova sensibilidade (1969), Marcuse afirma a possibilidade de uma revolução qualitativa essencialmente diferente das que já haviam ocorrido, pois baseia-se na dimensão estética para a criação de uma sensibilidade nova: na libertação dos sentidos a emergência de uma sensibilidade humanizada como guia da razão na reconstrução qualitativa da realidade. Nesse novo patamar de desenvolvimento, a sensibilidade guiaria a prática da ciência e da técnica, modificando a direção da produção material e intelectual para os fins da libertação e da pacificação da luta pela existência. Pode-se afirmar que, basicamente, a nova sensibilidade projetada por Marcuse é uma sensibilidade estético-política, referindo-se aos sentidos não mais como receptáculos passivos, mas como participantes ativos na construção da experiência e da subjetividade, o que demonstra a importante ligação desse trabalho com as teses desenvolvidas em Eros e civilização (1975).

No entanto, o fator que parece emergir como exigência primordial é a importância da imaginação e dos processos da consciência, que devem sustentar como força diretriz as possibilidades transcendentes de liberdade que preparem o terreno para a revolução (Marcuse, 1969). Tal tese se ampara na premissa marcuseana da potencialidade subversiva das estruturas pulsionais e na dinâmica sociológica da repressão: como baseia-se em uma repressão interna, resultado da interiorização da autoridade; para que a gestão da nova sensibilidade se dê, é preciso antes libertar-se internamente.

A consciência libertada resultante de um processo de educação estética poderia guiar a imaginação na transformação da ciência e da tecnologia. Assim, torna-se livre do jugo da racionalidade instrumental e passa a direcionar sua força para "descobrir e realizar as potencialidades das coisas e dos homens, na proteção e no gozo da vida, jogando com as potencialidades da forma e da matéria para - alcance desta meta" (Marcuse, 1969, p.31, tradução nossa). 0 novo conceito de imaginação a que se refere Marcuse diz respeito a uma imaginação ligada, sobretudo, às estruturas instintuais, aos sentidos libertados da racionalidade 
dominadora.

Se, como Marcuse argumenta, a razão já não mais corresponde à noção bidimensional clássica e sua transmutação em racionalismo tem gerado crises mais gerais na ciência e na sociedade, então somente o desenvolvimento de uma noção mais autoconsciente de razão, que contenha elementos de crítica assim como de necessidade de liberdade e ação transformativa, poderão libertar o pensamento e a investigação que tenham por fim a emancipação do homem. Nesse sentido, a dimensão estética, e sua dupla conotação de pertencente aos sentidos e à arte, pode servir para designar a qualidade do processo produtivo em um meio ambiente de liberdade. Nessa necessidade de transformação da razão reside o esforço de Marcuse em situar a reflexão crítica como um elemento fundamental na luta pela emancipação. Conforme Pucci (2003), esse conceito de razão tornase educativo em dois sentidos: no esclarecimento dos mecanismos de alienação e de manipulação ideológica, e na revelação de verdades não intencionais que poderiam conter "imagens fugidias" de uma sociedade diferente. Na medida em que a busca pela emancipação social é obstruída pela racionalidade instrumental, o sentido fundamental da educação para a emancipação está na descoberta do nexo entre dominação e racionalidade. A partir daí, a educação só pode ser efetivada nos termos da reconstrução crítica da racionalidade social, apreendendo as suas contradições, para assim poder extrair as suas possibilidades alternativas.

Em virtude das qualidades transformadoras da dimensão estética, Marcuse (1969) a qualifica como uma espécie de calibrador para uma sociedade livre. E, se uma sociedade livre implica a inexistência de qualquer espécie de exploração competitiva ou terror, exige-se a formação de uma sensibilidade livre das satisfações repressivas das sociedades sem liberdade, uma sensibilidade receptiva às formas e modos de realidade que até então haviam sido projetados pela imaginação estética. Esse é um dos pontos principais da nova sensibilidade: a libertação da imaginação para a projeção de um princípio da realidade não repressivo. Na sociedade industrial, a imaginação é cooptada, sendo-lhe infligido um caráter racionalista e científico, que, juntamente com o sistema material, milita contra a criação de um novo sujeito, capaz de posicionar-se criticamente perante as determinações da sociedade tecnocrata.

Na construção da nova sensibilidade, a imaginação é convertida em demandas da ação política, e, ao fazer isso, alcança a dimensão estética, mantida até então como apolítica. 0 protesto reativa nessa dimensão precisamente seus elementos: ao invocar o poder sensual da imaginação, a sensibilidade rebela-se contra os ditames da razão repressiva (Marcuse, 1969). Essa ação faz surgir a perspectiva de uma nova relação entre sensibilidade e razão na transformação da realidade na medida em que as faculdades racionais, capazes de projetar e definir as condições 
objetivas, sejam configuradas pela imaginação estética.

A libertação da sensibilidade e da sensualidade, não como um fator privado, mas sim como uma força para a transformação da existência humana, significa a valorização da vida como um fim em si mesma, e não um meio para alcançar um fim (Marcuse, 1986). É importante ressaltar que a nova sensibilidade não é uma característica particular, privada, pois assim corresponderia à cultura afirmativa que enquadra na interioridade as contradições, impedindo a evasão da sensibilidade para o plano objetivo. Trata-se de uma sensibilidade coletiva que penetra na imaginação para convertê-la em força transformadora.

\section{Considerações finais}

Se a filosofia de Marcuse atacou frontalmente o capitalismo, era por ser este a fonte da maioria da servidão a que é submetida a humanidade, um sistema que possui como base de sustentação a manutenção do sistema de sujeição e reificação. No entanto, tal crítica não pode jamais ser classificada com niilista, pois, ao passo que apresenta a humanidade como presa às amarras do lucro, também oferece uma ampla perspectiva de superação desse estado mediante a redefinição do conceito de razão adotado pela sociedade. Conforme Marcuse, a substituição dessa concepção por outra baseada na bidimensionalidade de Eros e Logos, que se expressa mais claramente na dimensão estética, representaria a elevação da humanidade a um patamar de crescimento qualitativo em que o potencial tecnológico da civilização seria direcionado para a pacificação da luta pela existência.

Na mediação com os clássicos, a percepção estética é aguçada para que ocorra não somente uma apropriação crítica da realidade, mas também uma interação transformadora. No âmbito da ciência, a arte propicia a criação de uma sensibilidade que se reflete na transformação qualitativa da técnica, orientando-a para a meta da pacificação da luta pela existência. Com base na revolta instintual, é uma premissa da nova sensibilidade a afirmação dos instintos de vida (Eros), que encontrariam expressão racional (sublimação), no planejamento da distribuição do tempo de trabalho socialmente necessário à produção, determinando as prioridades dos objetivos e seleções: não somente o que se deve produzir, mas também a forma do produto. Nesse sentido, não se trata meramente de conceituar uma totalidade ideal, mas de observar o concreto e o abstrato simultaneamente e, assim, ter a teoria como guia essencial para a prática.

As teses marcuseanas acerca da necessidade de valorização dos âmbitos 
não científicos do pensamento recaem na premissa central da transformação da concepção de razão adotada pela sociedade estabelecida, o que torna extremamente relevante o estudo da obra de Marcuse na contemporaneidade. A sua utilização pela teoria educacional promove um debate profícuo em torno da ideia de razão emancipatória. A ênfase de Marcuse na crítica, não somente às condições objetivas da dominação, mas também à dominação embutida nas formas subjetivas da racionalidade social, possibilita uma teoria educacional que coloque como objetivo principal a crítica e a resistência às formas pelas quais a racionalidade social é instrumentalizada, com o objetivo de manutenção de uma determinada estrutura de poder. Por conseguinte, uma prática política de transformação da realidade sem a permanente crítica da racionalidade, sem a transformação da subjetividade, não é uma prática emancipatória.

Em virtude das considerações apresentadas anteriormente, pode-se agora afirmar que a educação estética marcuseana constitui um conceito de formação que se pauta essencialmente pela ênfase no fomento ao pensamento crítico. Como âmbito centrado na contradição com a realidade, a arte provoca subjetivamente nos sujeitos a visão da realidade ora como ela é, ora como deveria ser. Dessa forma, a arte permite o desenvolvimento de uma relação com a realidade sob a forma de uma dialética negativa: o universo criado pela dimensão estética é reconhecido como uma realidade suprimida e distorcida da realidade existente, à qual a arte responde com a imagem bela de uma realidade emancipada. A experiência fomentada pela formação estética culmina na emergência de uma racionalidade e sensibilidade diferentes daquelas vigentes na sociedade unidimensional: movida pela crítica, a racionalidade não se satisfaz com o que é meramente dado, mas gera inquietação e necessidade de mudança.

A crise moral enfrentada pela contemporaneidade demostra a lacuna aberta por um modelo educacional deficitário, que, pautado na formação profissional, deixa em segundo plano a formação dos indivíduos em sentido pleno. No entanto, a teoria educacional subscrita na obra marcuseana revela a importância de que, em um panorama no qual a dominação do sistema de falsas necessidades e o pensamento unidimensional se impõem de forma tão determinante sobre os indivíduos, somente processos formativos permitiriam a criação de uma resistência à dominação. Pautada na crítica, essa resistência exige para o seu surgimento um processo de formação em um sentido amplo: que permita ao sujeito o desenvolvimento pleno de suas capacidades intelectuais, estéticas e morais, capaz de situar a ação humana não apenas na adaptação, mas, essencialmente, na transformação da existência a favor dos objetivos do desenvolvimento qualitativo. 


\section{Referências}

DUARTE, Newton; SAVIANI, Demerval (Orgs.). Pedagogia histórico-crítica e luta de classes na educação escolar. Campinas, SP: Autores Associados, 2012.

GIROUX, Henry. Para além das teorias da reprodução: teoria crítica e resistência em educação. Trad. Ângela Maria B. Biaggio. Rio de Janeiro: Vozes, 1986.

MAAR, Wolfgang Leo. A Formação em questão: Lukács, Marcuse e Adorno. In: ZUIN, Antônio A. S. (Org.). A Educação Danificada. 1ed. São Carlos/Petrópolis: Edufscar/Vozes, 1998. pp. 45-88.

. Educação crítica, formação cultural e emancipação política. In: PUCCI, Bruno (org.). Teoria crítica e educação: a questão da formação cultural na escola de Frankfurt. Petrópolis, Rio de Janeiro: Editora Vozes, 2003. pp. 61-80.

MARCUSE, Herbert. Un ensayo sobre la liberación. Trad. de Juan García Ponce. México: Cuadernos de Joaquín Mortiz, 1969.

. Eros e civilização: uma interpretação filosófica do pensamento de Freud. Trad.

Álvaro Cabral. Rio de Janeiro: Zahar, 1975.

. A dimensão estética. Trad. de Maria Elisabete Costa. Lisboa: Edições 70, 1977.

. A ideologia da sociedade industrial: o homem unidimensional. Trad. de Giasone

Rebuá. Rio de Janeiro: Zahar Editores, 1978.

. Ensayos sobre política y cultura. Barcelona: Planeta-Agostini, 1986.

. Cultura e sociedade Vol. II. Trad. de Wolfgang Leo Maar; Isabel Loureiro;

Robespierre de Oliveira. São Paulo: Editora Paz e Terra, 1998.

NICOLAS, André. Marcuse ou a busca de um universo transprometeico. Trad. de Franco de Sousa. Lisboa: Estúdios cor, 1971.

PUCCl, Bruno (org). Teoria crítica e educação: a questão da formação cultural na escola de Frankfurt. Petrópolis, Rio de Janeiro: Editora Vozes, 2003.

STEDEROTH, Dirk. Educação a partir da unidimensionalidade: contribuição de H. Marcuse para uma teoria educacional crítica. In: DALBOSCO, Claudio Almir; FLICKINGER, HansGeorg (orgs). Educação e maioridade: dimensões da racionalidade pedagógica. São Paulo, Cortez: Passo Fundo: Editora UPF, 2003. pp. 328-347.

Recebido em fevereiro de 2015

Aprovado em maio 2015

Vivian Baroni é Mestre e doutoranda em educação pelo PPGEdu da Universidade de Passo Fundo (UPF) e atua na área de Filosofia da Educação com ênfase em educação estética. E-mail: vivianbaroniahotmail.com 